\title{
Linkage and Association Analyses of Schizophrenia with Genetic Variations on Chromosome 22q11 in Koreans
}

\author{
Se Chang Yoon', Yong Lee Jang², Jong-Won Kim³, Eun-Young Cho ${ }^{4}$, \\ Dong Yeon Park ${ }^{5}$ Kyung Sue Hong', and Yu Sang Lee ${ }^{6} \bowtie$ \\ ${ }^{1}$ Department of Psychiatry, Sungkyunkwan University School of Medicine, Samsung Medical Center, Seoul, Republic of Korea \\ ${ }^{2}$ Department of Psychiatry, Seoul Medical Center, Seoul, Republic of Korea \\ ${ }^{3}$ Department of Laboratory Medicine and Clinical Genetics, Sungkyunkwan University School of Medicine, Samsung Medical Center, Seoul, \\ Republic of Korea \\ ${ }^{4}$ Samsung Biomedical Research Institute, Samsung Medical Center, Seoul, Republic of Korea \\ ${ }^{5}$ Department of Psychiatry, Seoul Mental Hospital, Seoul, Republic of Korea \\ ${ }^{6}$ Department of Psychiatry, Yong-In Mental Hospital, Yongin, Republic of Korea
}

Objective Chromosome 22q11 has been implicated as a susceptibility locus of schizophrenia. It also contains various candidate genes for which evidence of association with schizophrenia has been reported. To determine whether genetic variations in chromosome $22 \mathrm{q} 11$ are associated with schizophrenia in Koreans, we performed a linkage analysis and case-control association study.

Methods Three microsatellite markers within a region of $4.35 \mathrm{Mb}$ on $22 \mathrm{q} 11$ were genotyped for 47 multiplex schizophrenia families, and a non-parametric linkage analysis was applied. The association analysis was done with 227 unrelated patients and 292 normal controls. For 39 single nucleotide polymorphisms (SNPs) spanning a $1.4 \mathrm{Mb}$ region (33 kb interval) containing four candidate schizophrenia genes (DGCR, COMT, PRODH and ZDHHC8), allele frequencies were estimated in pooled DNA samples.

Results No significant linkage was found at any of the three microsatellite markers in single and multi-point analyses. Five SNPs showed suggestive evidence of association $(\mathrm{p}<0.05)$ and two more SNPs showed a trend for association $(\mathrm{p}<0.1)$ in pooled DNA association analysis. Individual genotyping was performed for those seven SNPs and four more intragenic SNPs. In this second analysis, all of the 11 SNPs individually genotyped did not show significant association.

Conclusion The present study suggests that genetic variations on chromosome 22q11 may not play a major role in Korean schizophrenia patients. Inadequate sample size, densities of genetic markers and differences between location of genetic markers of linkage and association can contribute to an explanation of the negative results of this study.

Psychiatry Investig 2016;13(6):630-636

Key Words Schizophrenia, Chromosome 22q11, Linkage, Association.

\section{INTRODUCTION}

Schizophrenia is a chronic debilitating mental disorder affecting up to $1 \%$ of the general population. Evidence from genetic epidemiological studies has suggested that genetic factors play a major role in determining the susceptibility to schizophrenia. ${ }^{1,2}$ Modest evidence of linkage with schizophre-

Received: August 12, 2015 Revised: December 30, 2015

Accepted: February 12, 2016 Available online: November 2, 2016

$\triangle$ Correspondence: Yu Sang Lee, MD, PhD

Department of Psychiatry, Yongin Mental Hospital, 940 Jungbu-daero, Giheunggu, Yongin 17089, Republic of Korea

Tel: +82-31-288-0114, Fax: +82-31-288-0180, E-mail: yusanglee@gmail.com

(a) This is an Open Access article distributed under the terms of the Creative Commons Attribution Non-Commercial License (http://creativecommons.org/licenses/bync/3.0) which permits unrestricted non-commercial use, distribution, and reproduction in any medium, provided the original work is properly cited. nia has been reported for several chromosomal loci from genome-wide linkage scans. Chromosome $22 \mathrm{q}$ is one candidate genomic region. However, the positive linkage signals yielded from this region are weak and encompass a broad region of chromosome 22q11-13..$^{3-7}$ In addition, linkage was not found in studies that specifically tested this region. ${ }^{8-10}$

Another notable finding related to this region and schizophrenia is that $25-31 \%$ of patients with velo-cardio-facial syndrome (VCFS) caused by the microdeletions of 22q11 have early-onset psychotic symptoms. ${ }^{11,12}$ This locus, especially the 1.4-1.5 Mb region of chromosome 22q11, has also been implicated in association studies. The catechol-O-methyltransferase (COMT) gene is a long-known functional candidate gene of schizophrenia that still shows very controversial results from association studies with various populations. ${ }^{13}$ More 
recent studies have identified genes for proline dehydrogenase $(P R O D H)^{14,15}$ and zinc finger domain DHHC domain containing $8(\mathrm{ZDHHC} 8)^{16,17}$ as candidate schizophrenia susceptibility genes from this locus. Especially, the ZDHHC8 rs175174 polymorphism may function in cortical volume in schizophrenia. ${ }^{18}$

Given that epidemiologic data on schizophrenia favor the contribution of multiple genes, each exerting a small-to-moderate effect on overall disease risk, controversial results from independent association or linkage studies are only to be expected. Concerning chromosome 22q and schizophrenia, inconsistent results were generated by different populations, even in a single study, which tested combined population samples. ${ }^{9,19,20}$ To resolve this issue, cumulative data generated by independent investigations of homogenous populations using their own background genetic data and homogenous clinical evaluation system are required.

The purpose of this study was to determine whether genetic variations in chromosome 22q11 are associated with schizophrenia in Koreans. We tested the linkage with schizophrenia using three microsatellite markers in multiplex schizophrenia families. A two-stage case-control association study was also conducted involving an initial screening for 39 SNPs with a $33 \mathrm{~kb}$ interval using pooled DNA samples and confirmation analysis using individual genotyping.

\section{METHODS}

\section{Subjects}

Recruitment of multiplex families containing two or more affected individuals among second degree relatives was performed through proband screening at Samsung Medical Center, Yong-In Mental Hospital, National Chuncheon Hospital and other mental hospitals and psychiatric clinics in Korea. The clinical assessment procedures used were described previously. ${ }^{21,22}$ We limited the diagnosis of the probands to schizophrenia according to the DSM-IV criteria. Affectation status was assigned as broad and narrow liability classes. For the broad class, the affected individuals other than the probands were diagnosed as having schizophrenia, schizoaffective disorder or schizotypal personality disorder according to DSM-IV. In the case of schizoaffective disorder and schizotypal personality disorder, only those cases in which longterm maintenance with antipsychotics was needed were included. The narrow class included those families in which all of the affected individuals met the DSM-IV criteria of schizophrenia. Following the exclusion of one family showing bilineal transmission of psychoses, the clinical data and DNA samples were analyzed from 47 families with 161 members including 105 affected individuals. Among these families, 40 (containing 138 members including 89 affected individuals) also belonged to the narrow class.

For the case-control association study, unrelated schizophrenia patients were recruited from Samsung Seoul Hospital, Yong-In Mental Hospital and National Chuncheon Hospital. Diagnostic Interview for Genetic Studies clinical interviews and best estimate diagnosis were performed by the same raters and psychiatrists who assessed the multiplex families. DSM-IV schizophrenia patients $(\mathrm{n}=227)$ were analyzed. Also, 292 normal control persons were recruited and screened for any psychiatric illnesses by means of a brief unstructured interview. The male-to-female ratio of the case and control group was 1.20 and 1.10 , respectively $\left(\chi^{2}=0.21, \mathrm{df}=1, \mathrm{p}=0.65\right)$. There was no significant difference between the mean age of the case and control groups ( $33.2 \pm 9.6$ and $33.5 \pm 8.9$ years, respectively; $\mathrm{t}=0.046, \mathrm{p}=0.96$ ). The average age at onset of patients with schizophrenia was $25.7 \pm 7.0$ years (range, 13-49). This study was approved by the institutional review boards of Samsung Medical Center and Yong-In Mental Hospital. Informed consent was obtained from all of the subjects who participated in the interviews and blood sampling.

\section{Genotyping for linkage analysis}

Three microsatellite markers spanning a region of $4.35 \mathrm{Mb}$ between 22q11.1 and 22q11.22 were selected (Figure 1) based on their heterozygosities and distances from each other (Table 1). The markers have a $5.86 \mathrm{cM}$ average interval according to the deCODE map. Their heterozygosities were calculated from the genotype data of one-hundred normal Koreans (generated by one of the authors; JWK) and from the unaffected founders of the families of the current study (Table 1). Genotypes were obtained for a broad class of 47 multiplex families with 161 members including 105 affected individuals. DNA was extracted from the white cells of peripheral blood by a Wizard ${ }^{\mathrm{TM}}$ Genomic DNA Purification kit (Promega, Madison, WI, USA). In the polymerase chain reaction (PCR), primer sets used were provided by the $\mathrm{ABI}^{\mathrm{PRISM}}$ linkage mapping set v2.5 (Applied Biosystems, Foster City, CA, USA) for D22S420 and D22S539. For D22S427, the primer set was designed using Primer 3 primer-designing software (http://frodo.wi.mit.edu/cgi-bin/primer3/primer3-www.cgi). All of the fluorescently labeled PCR products, by each forward primer, were separated by capillary electrophoresis on an ABI3100 Genetic Analyzer (Applied Biosystems). The results of the automatic scoring of the genotype peaks provided by "Genotyper" program (Applied Biosystems) were manually checked by referring to the distribution patterns of the peaks. Quality control of genotyping utilized DNA sample of CEPH 1347-02 in the assays, with manual checking of the Mendelian transmission for all of the markers and families. 


\section{Genotying for association studies}

Initially, an association study using pooled genotyping was done for 39 SNPs (35 intergenic and four intragenic SNPs) with a mean inter-marker distance of $33 \mathrm{~kb}$ spanning a $1.4 \mathrm{Mb}$ region of 22q11, which contains four candidate schizophrenia genes (DGCR6, PRODH, COMT, and ZDHHC8) (Figure 1). DNA pools were constructed separately for 227 patients and 292 control subjects as previously outlined. ${ }^{23,24}$ Concentrations of all DNA samples used for pool construction were determined using the PicoGreen dsDNA Quantitation method (Molecular Probes, Eugene, OR, USA) in a Labsystems Ascent Fluoroskan (Life Sciences international, Basingstoke, UK). Three microliters of a DNA suspension (20 ng/uL) from each individual was used to construct DNA pools. Genotyping of DNA pools were performed using SNapShot primer extension method (Applied Biosystems) as previously described ${ }^{23}$ for each SNP. PCR and extension primers were designed using MassARRAY assay design software (Sequenom, San Diego, CA, USA). Each pooled DNA sample was genotyped four times and average allele frequencies were calculated.

Individual genotyping with all samples included in the pools was performed for SNPs with a trend of association at $\mathrm{p}<0.1$ and four more intra-genic SNPs (Table 2). Genotyping of all the SNPs, except for two on $P R O D H$, were performed with the SNapShot assay (Applied Biosystems). PRODH*1945 $\mathrm{T} \rightarrow \mathrm{C}$ and $1766 \mathrm{~A} \rightarrow \mathrm{G}$ SNPs were genotyped using the PCRrestriction fragment length polymorphism method. A $499 \mathrm{bp}$ DNA fragment containing the $P R O D H^{*} 1945 \mathrm{~T} \rightarrow \mathrm{C}$ polymorphism was amplified using the forward primer 5'-CTCCCT GGTGCGATGGGGTAC-3' and reverse primer 5'-GGGCC CACACATTCG-AGGAG-3', followed by digestion with $P v u$ II (Roche, Basel, Switzerland). The digestion products were scored as cut and uncut type $\left(1945^{*} \mathrm{C}\right.$ allele and $1945^{*} \mathrm{~T}$ allele, respectively). A 263 bp DNA fragment containing the $P R O D H^{*} 1766 \mathrm{~A} \rightarrow \mathrm{G}$ was amplified using the forward primer 5'-GGGACAG- TGTCCTGGAACTG-3' and reverse primer 5'-CATCACGGGGCCATAGGGCAC-3', followed by digestion with Nci I (New England Biolabs, Ipswich, MA, USA). The scored cut and uncut type was $1766^{*} \mathrm{G}$ allele and $1766^{*} \mathrm{~A}$ allele, respectively.

\section{Statistical analysis: linkage analysis}

The model-free linkage analysis was performed using Genehunter 2.1_r4 $\beta .^{25}$ Both the single point and multi-point $\mathrm{NPL}_{\text {all }}$ scores were calculated by an affected-only allele-sharing method. This analysis does not have the context of a ge-

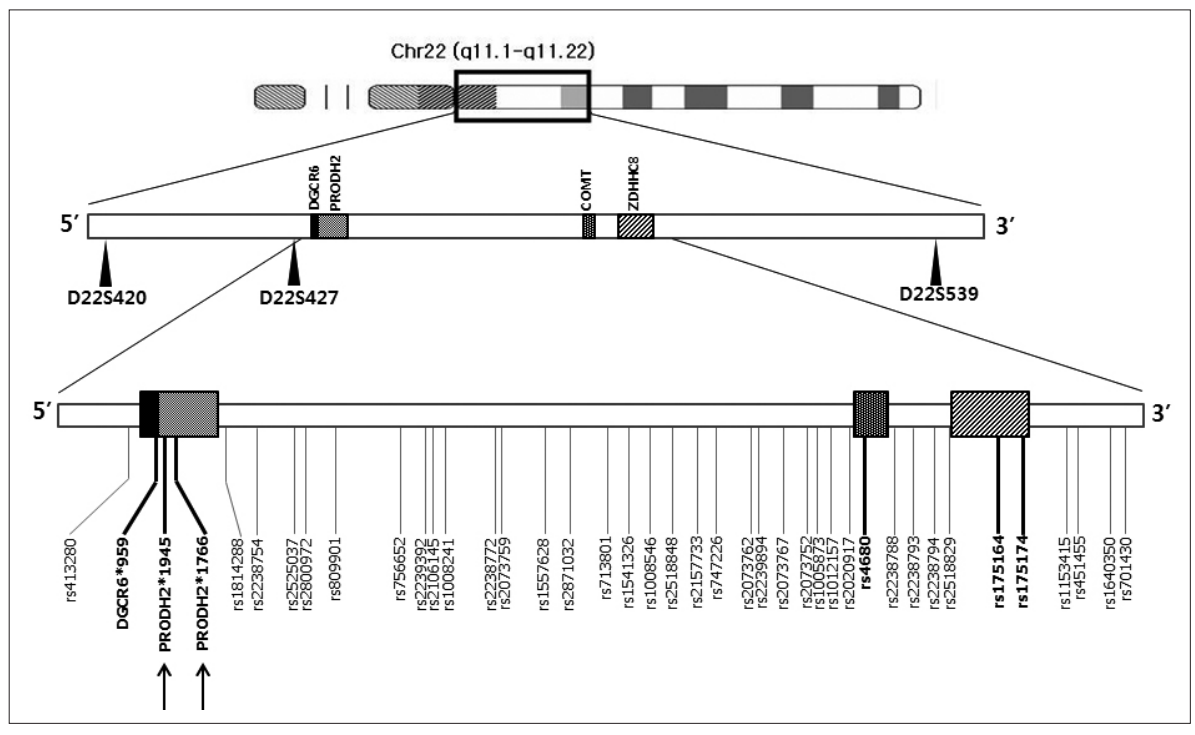

Figure 1. The location of microsatellite markers (spanning $4.35 \mathrm{Mb}$ ) and SNPs (spanning $1.40 \mathrm{Mb}$ ) used for linkage and association analyses of the present study with known candidate genes of schizophrenia in chromosome 22q11. Intra-genic SNPs on candidate genes are indicated in bold. Arrows represent the SNPs analyzed only by individual genotyping. SNP: single nucleotide polymorphisms.

Table 1. Results of the single point linkage analysis: non-parametric lod (NPL) scores and pointwise p-values

\begin{tabular}{|c|c|c|c|c|c|c|c|}
\hline \multirow{3}{*}{ Markers } & \multirow{3}{*}{$\begin{array}{c}\text { Genetic distance } \\
(\mathrm{cM})^{*}\end{array}$} & \multirow{2}{*}{\multicolumn{2}{|c|}{ Heterozygosities }} & \multicolumn{4}{|c|}{ Phenotype classes } \\
\hline & & & & \multicolumn{2}{|c|}{ Broad } & \multicolumn{2}{|c|}{ Narrow } \\
\hline & & Population $^{\dagger}$ & Families ${ }^{\ddagger}$ & NPL & $\mathrm{p}$ & NPL & $\mathrm{p}$ \\
\hline $\mathrm{D} 22 \mathrm{~S} 420$ & - & 0.73 & 0.74 & 0.35 & 0.36 & 0.17 & 0.43 \\
\hline $\mathrm{D} 22 \mathrm{~S} 427$ & 2.84 & - & 0.58 & -0.59 & 0.73 & -0.72 & 0.76 \\
\hline D22S539 & 8.88 & 0.56 & 0.52 & 0.23 & 0.41 & 0.31 & 0.38 \\
\hline
\end{tabular}

*represents the genetic distance (based on the deCODE map) from the previous marker, ${ }^{\dagger}$ calculated from the genotype data of a normal Korean population, ${ }^{\ddagger}$ calculated from the genotype data of the unaffected founders of the Korean schizophrenia families 
nome-wide linkage mapping, and we adopted the pointwise $\mathrm{p}$-value to evaluate the statistical significance. The marker distances obtained from the deCODE map were adopted. The marker allele frequencies were calculated from the Korean population data described above, except for D22S427. For this marker, allele frequencies were calculated from the genotypes of the unaffected founders of the families recruited for the current analysis.

\section{Statistical analysis: association studies}

The genotypic distribution of each marker tested for the association studies was not significantly different from that ex- pected based on the Hardy-Weinberg equilibrium in either the case or control group (SAS Genetics v 8.02). In the initial screening with pooled DNA samples, peak heights of the SNaPshot products in a pool of case DNA and in a pool of control DNA samples were measured. The frequency $\mathrm{f}$ of allele A was calculated as $f(A)=H_{A} /\left(H_{A}+k H_{B}\right)$, where $H_{A}$ and $H_{B}$ are the peak heights of the SNaPshot products representing alleles $A$ and $B$. A correction factor $(k)$, the ratio of the peak heights in the heterozygous sample $\left(H_{A} / H_{B}\right)$, was used to correct for systematic unequal representation of alleles that occurred with most genotyping methods. This was estimated from 8-16 independent heterozygotes samples that were individually genotyped.

Table 2. Results of association analysis for markers genotyped with individual DNA samples

\begin{tabular}{|c|c|c|c|c|c|c|c|}
\hline \multirow{2}{*}{$\begin{array}{r}\text { Group } \\
\text { PRODH*1945 }^{*}\end{array}$} & \multicolumn{2}{|c|}{ Allele: number (\%) } & \multirow[t]{2}{*}{$\chi^{2}(\mathrm{df}=1)$} & \multicolumn{3}{|c|}{ Genotype: number (\%) } & \multirow[t]{2}{*}{$\chi^{2}(\mathrm{df}=2$} \\
\hline & $\mathrm{C}$ & $\mathrm{T}$ & & $\mathrm{CC}$ & $\mathrm{CT}$ & TT & \\
\hline Case $(\mathrm{N}=215)$ & $94(21.86)$ & $336(78.14)$ & 0.07336 & $9(4.19)$ & $76(35.35)$ & $130(60.47)$ & 0.9372 \\
\hline Control $(\mathrm{N}=279)$ & $118(21.15)$ & $440(78.85)$ & & $10(3.58)$ & $98(35.13)$ & $171(61.29)$ & \\
\hline PRODH*1766 & A & G & & AA & AG & GG & \\
\hline Case $(\mathrm{N}=215)$ & $410(95.35)$ & $20(4.65)$ & 0.0000 & $195(90.70)$ & $20(9.30)$ & $0(0.00)$ & 0.9950 \\
\hline Control (N=279) & $532(95.34)$ & $26(4.66)$ & & $253(90.68)$ & $26(9.32)$ & $0(0.00)$ & \\
\hline rs1008241 & $\mathrm{C}$ & G & & $\mathrm{CC}$ & CG & GG & \\
\hline Case $(\mathrm{N}=215)$ & $232(53.95)$ & $198(46.05)$ & 0.61837 & $59(27.44)$ & $114(53.02)$ & $42(19.53)$ & 0.6745 \\
\hline Control $(\mathrm{N}=279)$ & $287(51.43)$ & $271(48.57)$ & & $67(24.01)$ & $153(54.84)$ & $59(21.15)$ & \\
\hline rs2073762 & $\mathrm{C}$ & $\mathrm{T}$ & & $\mathrm{CC}$ & $\mathrm{CT}$ & $\mathrm{TT}$ & \\
\hline Case $(\mathrm{N}=215)$ & $253(58.84)$ & $177(41.16)$ & 0.34000 & $69(32.09)$ & $115(53.49)$ & $31(14.42)$ & 0.2006 \\
\hline Control (N=279) & $318(56.99)$ & $240(43.01)$ & & $94(33.69)$ & $130(46.59)$ & $55(19.71)$ & \\
\hline rs2073767 & A & G & & $\mathrm{AA}$ & $\mathrm{AG}$ & GG & \\
\hline Case $(\mathrm{N}=215)$ & $260(60.47)$ & $170(39.53)$ & 1.33548 & $76(35.35)$ & $108(50.23)$ & $31(14.42)$ & 0.3968 \\
\hline Control (N=279) & $317(56.81)$ & $241(43.19)$ & & $91(32.62)$ & $135(48.39)$ & $53(19.00)$ & \\
\hline rs2073752 & A & G & & AA & AG & GG & \\
\hline Case $(\mathrm{N}=215)$ & $163(37.91)$ & $267(62.09)$ & 0.06805 & $31(14.42)$ & $101(46.98)$ & $83(38.60)$ & 0.9374 \\
\hline Control (N=279) & $207(37.10)$ & $351(62.90)$ & & $40(14.34)$ & $127(45.52)$ & $112(40.14)$ & \\
\hline rs4680(COMT) & A & G & & $\mathrm{AA}$ & $\mathrm{AG}$ & GG & \\
\hline Case $(\mathrm{N}=215)$ & $110(25.58)$ & $320(74.42)$ & 0.21177 & $10(4.65)$ & $90(41.86)$ & $115(53.49)$ & 0.2971 \\
\hline Control (N=279) & $150(26.88)$ & $408(73.12)$ & & $22(7.89)$ & $106(37.99)$ & $151(54.12)$ & \\
\hline rs175164 (ZDHHC8) & A & G & & $\mathrm{AA}$ & AG & GG & \\
\hline Case $(\mathrm{N}=215)$ & $58(13.49)$ & $372(86.51)$ & 0.7277 & $4(1.86)$ & $50(23.26)$ & $161(74.88)$ & 0.8817 \\
\hline Control $(\mathrm{N}=279)$ & $72(12.90)$ & $486(87.10)$ & & $6(2.15)$ & $60(21.51)$ & $213(76.34)$ & \\
\hline rs175174 (ZDHHC8) & A & G & & AA & AG & GG & \\
\hline Case $(\mathrm{N}=215)$ & $160(37.21)$ & $270(62.79)$ & 0.18000 & $31(14.42)$ & $98(45.58)$ & $86(40.00)$ & 0.9011 \\
\hline Control $(\mathrm{N}=279)$ & $215(38.53)$ & $343(61.47)$ & & $42(15.05)$ & $131(46.95)$ & $106(37.99)$ & \\
\hline rs1153415 & A & G & & $\mathrm{AA}$ & AG & GG & \\
\hline Case $(\mathrm{N}=215)$ & $263(61.16)$ & $167(38.84)$ & 0.85883 & $76(35.35)$ & $111(51.63)$ & $28(13.02)$ & 0.6248 \\
\hline Control $(\mathrm{N}=279)$ & $325(58.24)$ & $233(41.76)$ & & $89(31.90)$ & $147(52.69)$ & $43(15.41)$ & \\
\hline rs701430 & C & $\mathrm{T}$ & & CC & CT & $\mathrm{TT}$ & \\
\hline Case $(\mathrm{N}=215)$ & $270(62.79)$ & $160(37.21)$ & 0.00046 & $79(36.74)$ & $112(52.09)$ & $24(11.16)$ & 0.7199 \\
\hline Control $(\mathrm{N}=279)$ & $350(62.72)$ & $208(37.28)$ & & $107(38.35)$ & $136(48.75)$ & $36(12.90)$ & \\
\hline
\end{tabular}


The frequency $f$ of allele B was calculated as 1-f(A). Estimated allele frequencies were converted to numbers and were tested for approximate statistical significance by $\chi^{2}$ analysis. For individual genotyping methods, genetic associations were also tested using Pearson $\chi^{2}$-test with the SAS statistical software package version 8.2 (SAS, Cary, NC, USA).

\section{Statistical power analysis}

The sample size of $80 \%$ power is used to avoid false negative associations in genetic association studies. The effective sample size and statistical power were computed assuming $1 \%$ prevalence rate of schizophrenia, 1 of D-prime (Linkage disequilibrium), odds ratio of 1.05-1.5 for a risk allele, 1:1 casecontrol ratio. User defined type I error rate was calculated for the 11 tested SNPs. Genetic Power Calculator software26 was used for the statistical power determination.

\section{RESULTS}

\section{Linkage analysis}

Mendelian inconsistency was detected in only one family. The family was excluded from the statistical analysis. Fortysix families with 157 members including 103 affected individuals were finally included in the statistical analysis. No significant linkage was found at any of the three markers in single and multi-point analyses (Table 1).

\section{Association study}

In the initial analysis with pooled DNA, five SNPs showed positive associations with schizophrenia: $r \mathrm{~s} 2073762(\mathrm{p}=0.01)$, rs2073767 ( $\mathrm{p}=0.0041), \mathrm{rs} 4680(\mathrm{p}=0.0133), \mathrm{rs} 1153415$ ( $\mathrm{p}=$

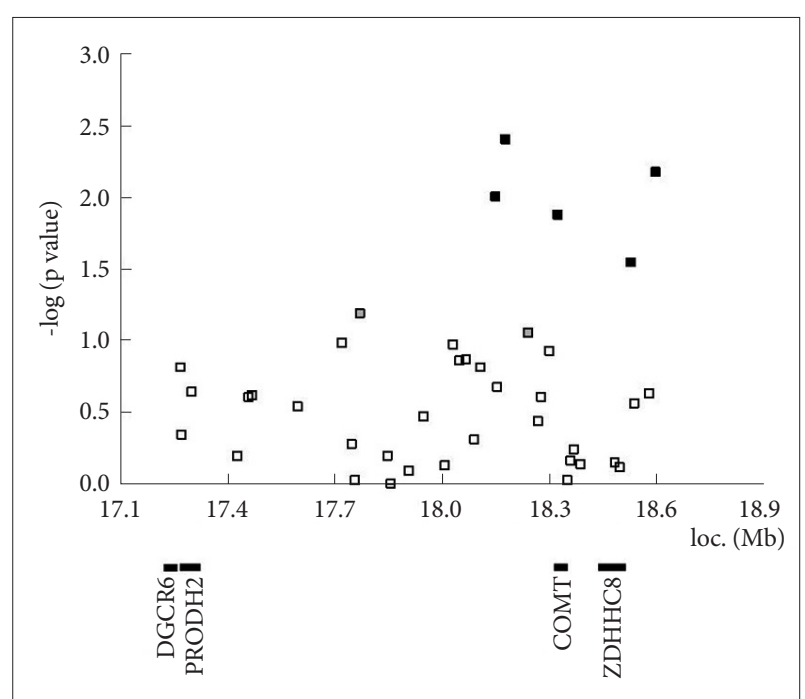

Figure 2. Results of association analysis with pooled DNA samples. Among 39 SNPs, five showed positive association with schizophrenia (black squares) and two showed only a trend of association (gray squares). SNP: single nucleotide polymorphisms.
0.0287) and rs701430 ( $\mathrm{p}=0.0068$ ) (Figure 2). Among these SNPs, rs4680 was located in the COMT gene and the others were inter-genic SNPs. Two more inter-genic SNPs showed a trend for association $(\mathrm{p}<0.1)$, i.e., $r \mathrm{~s} 1008241(\mathrm{p}=0.0656)$ and $\mathrm{rs} 2073752$ ( $\mathrm{p}=0.0883$ ). For those seven SNPs and four additional SNPs on $P R O D H$ and $Z D H H C 8$, genotyping with individual DNA samples were performed. In the association analysis, none of the SNPs showed significant association with schizophrenia (Table 2). The statistical power analysis showed the sample size was too small to achieve adequate statistical power. For instance, the statistical power to identify the evidence for association between rs207362 and schizophrenia after the Bonferroni correction under the assumptions of odds ratio for TT genotypes assuming a recessive model (1.44), risk allele frequency ( $41 \% \mathrm{LD}$ between the marker allele and the risk allele $=1$ ), disease prevalence (1\%) was estimated as $11.69 \%$. At least 1070 cases and 1391 controls were required to achieve $80 \%$ statistical power under the same assumption.

\section{DISCUSSION}

Presently, to assess chromosome 22q11 region as a candidate region for schizophrenia, we describe a linkage strategy and association analysis with a two-stage design. The latter analysis, in which positive marker loci from pooling study are followed by confirmatory individual genotyping, might represent the best trade-off between the cost savings of pooling and the full information that is provided by individual genotyping.

The 22q11 microdeletions have been postulated to be the most prominent genetic risk factor for the development of schizophrenia ${ }^{27}$ based on their increased prevalence in the disorder. Chromosome 22q11 is therefore believed to be a region that harbors susceptibility genes to schizophrenia, which is also supported by the results of independent linkage studies. Significant linkage score for several populations was reported beginning in $1994 .{ }^{3,5,9,28}$ However, other studies reported negative linkage to schizophrenia for this locus. ${ }^{8,10}$

Association studies have also been inconclusive. COMT, PRODH, ZDHHC8 and DGCR6 have been suggested as candidate genes in the development or heightened risk of schizophrenia. Thus, in the current two-stage association study we tried to include polymorphisms on those genes. However, our findings are consistent with prior studies that also failed to detect disease association at the COMT rs $4680,{ }^{23,30} \mathrm{PRODH}^{*}$ 1945 polymorphism, ${ }^{31-33}$ and ZDHHC8 rs $175174 . .^{34-36}$

Within all the intragenic SNPs examined in the pooling analysis, only rs4680 on COMT showed a positive trend for association. However, we failed to show same result for in the in- 
dividual genotyping. Several polymorphisms of COMT have been reported on the significant region; one is rs4680 SNP, a functional Valine to Methionine substitution on codon 158 (Val158Met). ${ }^{13,36,38}$ In addition, several functional analyses between the polymorphism and schizophrenia have reported significant results. Chen et al..$^{39}$ showed that the polymorphism affects the activity of COMT with the Met allele having lower activity. More recently, Ohnishi et al. ${ }^{40}$ suggested that this polymorphism might contribute to morphological abnormalities in schizophrenia.

$P R O D H$ has been suggested to increase susceptibility to schizophrenia because of abnormal findings in a $P R O D H$-mutant mouse, ${ }^{41,42} 350-\mathrm{kb}$ deletion that includes $P R O D H,{ }^{43}$ an allelic association with schizophrenia ${ }^{15,44}$ and identification of $P R O D H^{*} 1766 / 1945$ haplotype that is significantly associated with transmission disequilibrium. ${ }^{44}$

ZDHHC8 has been also proposed to increase liability to schizophrenia based on both an animal model and human association studies investigating rs175174(A/G) and schizophrenia. ${ }^{17}$ In addition, no association between schizophrenia and this SNP with overall /divided samples by gender have been reported. ${ }^{34,45}$ In an integrated analysis of multiple datasets, the ZDHHC8 rs175174 polymorphism was negatively associated with schizophrenia. ${ }^{46}$ These inconsistent findings with regard to the risk allele at rs175174 highlight the need for further studies of the functional effect of this SNP.

The interaction of contiguous genes on 22q11 might influence the etiology of schizophrenia, with 22q11-associated schizophrenia having the characteristics of a contiguous gene syndrome. Synergistic interaction among physically linked genes, which disrupts neuronal homeostatic plasticity, could in principle lead to the high disease risk associated with this locus and/or modulate the expression of the phenotype. ${ }^{41}$ Whether this hypothesis is true or not, it suggests that the interaction of multiple genes, each with a small-to-moderate effect, can pose an appreciable overall disease risk.

Unfortunately, our study found no evidence of linkage and association between schizophrenia and 22q11-candidate genes from both family-based and case-control samples in Koreans.

Limitations of this study should be kept in mind. First, the chromosomal region investigated was not narrow. It was 4.35 $\mathrm{Mb}$ and only three microsatellite markers were used for linkage study. In addition, the SNPs were not close enough to linkage disequilibrium with those microsatellite markers. Second, it seems that the linkage study and association study investigated different chromosomal area, even though they are in 22q11. The regions for the linkage study and associations study did not overlap in terms of genetic analysis. Third, the sample size was too small to achieve adequate statistical power.

In conclusion, the findings suggest that genetic variations on chromosome 22q11 may not play a major role in schizophrenia in Koreans. Inadequate sample size, densities of genetic markers and differences between location of genetic markers of linkage and association can contribute to an explanation of the negative results of this study.

\section{Acknowledgments}

This study was supported by grants from the Yongin Psychiatric Research Institute and the Korea Health 21 R\&D Project, Ministry of Health \& Welfare, Republic of Korea (A040042). We would like to thank Prof. Ji Wan Park and doctoral candidate Eun Pyo Hong in the Department of Medical Genetics at Hallym University College of Medicine for their contribution of statistical power determination.

\section{REFERENCES}

1. Cannon TD, Kaprio J, Lonnqvist J, Huttunen M, Koskenvuo M. The genetic epidemiology of schizophrenia in a Finnish twin cohort. A population-based modeling study. Arch Gen Psychiatry 1998;55:67-74.

2. Cardno AG, Gottesman II. Twin studies of schizophrenia: from bowand-arrow concordances to star wars Mx and functional genomics. Am J Med Genet 2000;97:12-17.

3. Coon H, Holik J, Hoff M, Reimherr F, Wender P, Myles-Worsley M, et al. Analysis of chromosome 22 markers in nine schizophrenia pedigrees. Am J Med Genet 1994;54:72-79.

4. DeLisi LE, Shaw SH, Crow TJ, Shields G, Smith AB, Larach VW, et al. A genome-wide scan for linkage to chromosomal regions in 382 sibling pairs with schizophrenia or schizoaffective disorder. Am J Psychiatry 2002;159:803-812.

5. Lasseter VK, Pulver AE, Wolyniec PS, Nestadt G, Meyers D, Karayiorgou M, et al. Follow-up report of potential linkage for schizophrenia on chromosome 22q: Part 3. Am J Med Genet 1995;60:172-173.

6. Lewis CM, Levinson DF, Wise LH, DeLisi LE, Straub RE, Hovatta I, et al. Genome scan meta-analysis of schizophrenia and bipolar disorder, part II: Schizophrenia. Am J Hum Genet 2003;73:34-48.

7. Pulver AE, Karayiorgou M, Lasseter VK, Wolyniec P, Kasch L, Antonarakis $\mathrm{S}$, et al. Follow-up of a report of a potential linkage for schizophrenia on chromosome 22q12-q13.1: Part 2. Am J Med Genet 1994; 54:44-50.

8. Kalsi G, Brynjolfsson J, Butler R, Sherrington R, Curtis D, Sigmundsson $\mathrm{T}$, et al. Linkage analysis of chromosome 22q12-13 in a United Kingdom/Icelandic sample of 23 multiplex schizophrenia families. Am J Med Genet 1995;60:298-301.

9. Pulver AE, Karayiorgou M, Wolyniec PS, Lasseter VK, Kasch L, Nestadt $\mathrm{G}$, et al. Sequential strategy to identify a susceptibility gene for schizophrenia: report of potential linkage on chromosome 22q12-q13.1: Part 1. Am J Med Genet 1994;54:36-43.

10. Riley B, Mogudi-Carter M, Jenkins T, Williamson R. No evidence for linkage of chromosome 22 markers to schizophrenia in southern African Bantu-speaking families. Am J Med Genet 1996;67:515-522.

11. Murphy KC, Jones LA, Owen MJ. High rates of schizophrenia in adults with velo-cardio-facial syndrome. Arch Gen Psychiatry 1999;56: 940-945.

12. Pulver AE, Nestadt G, Goldberg R, Shprintzen RJ, Lamacz M, Wolyniec PS, et al. Psychotic illness in patients diagnosed with velo-cardio-facial syndrome and their relatives. J Nerv Ment Dis 1994;182: 476-478.

13. Glatt SJ, Faraone SV, Tsuang MT. Association between a functional catechol O-methyltransferase gene polymorphism and schizophrenia: meta-analysis of case-control and family-based studies. Am J Psychiatry 2003;160:469-476.

14. Li T, Ball D, Zhao J, Murray RM, Liu X, Sham PC, et al. Family-based linkage disequilibrium mapping using SNP marker haplotypes: application to a potential locus for schizophrenia at chromosome 22q11. 
Mol Psychiatry 2000;5:77-84.

15. Li T, Ma X, Sham PC, Sun X, Hu X, Wang Q, et al. Evidence for association between novel polymorphisms in the PRODH gene and schizophrenia in a Chinese population. Am J Med Genet B Neuropsychiatr Genet 2004;129:13-15.

16. Chen WY, Shi YY, Zheng YL, Zhao XZ, Zhang GJ, Chen SQ, et al. Case- control study and transmission disequilibrium test provide consistent evidence for association between schizophrenia and genetic variation in the 22q11 gene ZDHHC8. Hum Mol Genet 2004;13:29912995.

17. Mukai J, Liu H, Burt RA, Swor DE, Lai WS, Karayiorgou M, et al. Evidence that the gene encoding ZDHHC8 contributes to the risk of schizophrenia. Nat Genet 2004;36:725-731.

18. Ota VK, Gadelha A, Assuncao IB, Santoro ML, Christofolini DM, Bellucco FT, et al. ZDHHC8 gene may play a role in cortical volumes of patients with schizophrenia. Schizophr Res 2013;145:33-35.

19. Mowry BJ, Holmans PA, Pulver AE, Gejman PV, Riley B, Williams $\mathrm{NM}$, et al. Multicenter linkage study of schizophrenia loci on chromosome 22q. Mol Psychiatry 2004;9:784-795.

20. Takahashi S, Cui YH, Kojima T, Han YH, Zhou RL, Kamioka M, et al. Family-based association study of markers on chromosome 22 in schizophrenia using African-American, European-American, and Chinese families. Am J Med Genet B Neuropsychiatr Genet 2003;120:11-17.

21. Kim JW, Lee YS, Cho EY, Jang YL, Park DY, Choi KS, et al. Linkage and association of schizophrenia with genetic variations in the locus of neuregulin 1 in Korean population. Am J Med Genet Part B: Neuropsych Genet 2006;141:281-286.

22. Jang YL, Kim JW, Lee YS, Park DY, Cho EY, Jeun HO, et al. Linkage of schizophrenia with chromosome 1q32 in Korean multiplex families. A J Med Genet Part B: Neuropsych Genet 2007;144:279-284.

23. Norton N, Williams NM, Williams HJ, Spurlock G, Kirov G, Morris DW, et al. Universal, robust, highly quantitative SNP allele frequency measurement in DNA pools. Hum Genet 2002;110:471-478.

24. Hoogendoorn B, Norton N, Kirov G, Williams N, Hamshere ML, Spurlock G, et al. Cheap, accurate and rapid allele frequency estimation of single nucleotide polymorphisms by primer extension and DHPLC in DNA pools. Hum Genet 2000;107:488-493.

25. Kruglyak L, Daly MJ, Reeve-Daly MP, Lander ES. Parametric and nonparametric linkage analysis: a unified multipoint approach. Am J Hum Genet 1996;58:1347-1363.

26. Purcell S, Cherny SS, Sham PC. Genetic Power Calculator: design of linkage and association genetic mapping studies of complex traits. Bioinformatics 2003;19:149-150.

27. Karayiorgou M, Morris MA, Morrow B, Shprintzen RJ, Goldberg R, Borrow J, et al. Schizophrenia susceptibility associated with interstitial deletions of chromosome 22q11. Proc Natl Acad Sci U S A 1995;92: 7612-7616.

28. Shaw SH, Kelly M, Smith AB, Shields G, Hopkins PJ, Loftus J, et al. A genome-wide search for schizophrenia susceptibility genes. Am J Med Genet 1998;81:364-376.

29. Fan JB, Zhang CS, Gu NF, Li XW, Sun WW, Wang HY, et al. CatecholO-methyltransferase gene Val/Met functional polymorphism and risk of schizophrenia: a large-scale association study plus meta-analysis. Biol Psychiatry 2005;57:139-144.

30. Munafo MR, Bowes L, Clark TG, Flint J. Lack of association of the COMT (Val158/108 Met) gene and schizophrenia: a meta-analysis of case-control studies. Mol Psychiatry 2005;10:765-770.
31. Fan JB, Ma J, Zhang CS, Tang JX, Gu NF, Feng GY, et al. A familybased association study of T1945C polymorphism in the proline dehydrogenase gene and schizophrenia in the Chinese population. Neurosci Lett 2003;338:252-254.

32. Williams HJ, Williams N, Spurlock G, Norton N, Ivanov D, McCreadie RG, et al. Association between PRODH and schizophrenia is not confirmed. Mol Psychiatry 2003;8:644-645.

33. Williams HJ, Williams N, Spurlock G, Norton N, Zammit S, Kirov G, et al. Detailed analysis of PRODH and PsPRODH reveals no association with schizophrenia. Am J Med Genet B Neuropsychiatr Genet 2003;120:42-46.

34. Glaser B, Schumacher J, Williams HJ, Jamra RA, Ianakiev N, Milev R, et al. No association between the putative functional ZDHHC8 single nucleotide polymorphism rs175174 and schizophrenia in large European samples. Biol Psychiatry 2005;58:78-80.

35. Saito S, Ikeda M, Iwata N, Suzuki T, Kitajima T, Yamanouchi Y, et al. No association was found between a functional SNP in ZDHHC8 and schizophrenia in a Japanese case-control population. Neurosci Lett 2005; 374:21-24.

36. Otani K, Ujike H, Tanaka Y, Morita Y, Kishimoto M, Morio A, et al. The ZDHHC8 gene did not associate with bipolar disorder or schizophrenia. Neurosci Lett 2005;390:166-170.

37. Lee SG, Joo Y, Kim B, Chung S, Kim HL, Lee I, et al. Association of Ala72Ser polymorphism with COMT enzyme activity and the risk of schizophrenia in Koreans. Hum Genet 2005;116:319-328.

38. Shifman S, Bronstein M, Sternfeld M, Pisante-Shalom A, Lev-Lehman E, Weizman A, et al. A highly significant association between a COMT haplotype and schizophrenia. Am J Hum Genet 2002;71:1296-1302.

39. Chen J, Lipska BK, Halim N, Ma QD, Matsumoto M, Melhem S, et al. Functional analysis of genetic variation in catechol-O-methyltransferase (COMT): effects on mRNA, protein, and enzyme activity in postmortem human brain. Am J Hum Genet 2004;75:807-821.

40. Ohnishi T, Hashimoto R, Mori T, Nemoto K, Moriguchi Y, Iida H, et al. The association between the Val158Met polymorphism of the catechol-O-methyl transferase gene and morphological abnormalities of the brain in chronic schizophrenia. Brain 2006;129:399-410.

41. Karayiorgou M, Gogos JA. The molecular genetics of the 22q11-associated schizophrenia. Brain Res Mol Brain Res 2004;132:95-104.

42. Paterlini M, Zakharenko SS, Lai WS, Qin J, Zhang H, Mukai J, et al. Transcriptional and behavioral interaction between 22q11.2 orthologs modulates schizophrenia-related phenotypes in mice. Nat Neurosci 2005;8:1586-1594.

43. Jacquet H, Raux G, Thibaut F, Hecketsweiler B, Houy E, Demilly C, et al. PRODH mutations and hyperprolinemia in a subset of schizophrenic patients. Hum Mol Genet 2002;11:2243-2249.

44. Liu H, Heath SC, Sobin C, Roos JL, Galke BL, Blundell ML, et al. Genetic variation at the 22q11 PRODH2/DGCR6 locus presents an unusual pattern and increases susceptibility to schizophrenia. Proc Natl Acad Sci U S A 2002;99:3717-3722.

45. Faul T, Gawlik M, Bauer M, Jung S, Pfuhlmann B, Jabs B, et al. ZDHHC8 as a candidate gene for schizophrenia: analysis of a putative functional intronic marker in case-control and family-based association studies. BMC Psychiatry 2005;5:35.

46. Xu M, St Clair D, He L. Testing for genetic association between the ZDHHC8 gene locus and susceptibility to schizophrenia: An integrated analysis of multiple datasets. Am J Med Genet B Neuropsychiatr Genet 2010;153B:1266-1275. 